\title{
Dynamics Affecting Career Choice: A Drift in the College of Business and Accountancy Campaign Plan
}

\author{
Kingie G. Micabalo ${ }^{1}$, Jesszon B. Cano ${ }^{2}$, Ryan D. Montilla ${ }^{3}$, June Ace P. Navarro ${ }^{4}$ and Edwin S. Compra ${ }^{5}$ \\ ${ }^{1,3,4 \& 5}$ Business and Accountancy, University of Cebu, Cebu City, Philippines \\ ${ }^{2}$ Bohol Island State University, Candijay, Philippines \\ E-mail:kmicabalo@uc.edu.ph, jesszon.cano@bisu.edu.ph,rmontilla@uc.edu.ph, janavarro@uc.edu.ph, escidea@yahoo.com
}

\begin{abstract}
Marketing campaigns maintain consistency among advertisements, promoting a unified brand message across all platforms. This consistency helps create a strong brand identity and voice. The examination decided the degree of the senior high school understudies' impression on the variables influencing their career decision as to personal factors, peer factors, family factors, and school factors. There are $\mathbf{2 0 0}$ respondents from the Senior High department using stratified random technique. Frequency and simple percentage, Weighted Mean, Chi-Square Test of Independence, were used to analyzed and interpret the data accumulated. The study revealed that personal factors, peer factors, and school factors are the most common perception in career decision making. At the same time, BSED in English, Accountancy, and Nursing are the most preferred courses. The study further revealed a statistically significant relationship between academic track and the students' perception on the factors that affect career choice. There is also a statistically significant relationship between personal factors, school factors, and the respondents' most preferred courses. The study concluded that senior high school students' must be guided to achieve a good decision pursuing courses offered by the Business and Accountancy department. A campaign program is inevitable to realize the set objectives higher and to prepare for future student encounters.
\end{abstract}

Keywords: Marketing, Campaign Plan, DescriptiveCorrelational, Mandaue City, Philippines

\section{INTRODUCTION}

A campaign plan is an arrangement to accomplish a goal, as a rule, for an enormous scope over an all-inclusive period. It usually coordinates many activities and uses of resources involving multiple organizations. A campaign plan could also have subordinate objectives or intermediate milestones and is often broken down by phases. They often begin with an assessment of the situation to put the plan in context. Campaign plans are often created in business marketing, political campaigning, and military campaigning. Marketing campaigns helps create a strong brand identity and voice. They maintain consistency among advertisements, promoting a unified brand message across all platforms. This consistency is critical to creating a brand, and customers are loyal to brands, not products. Most customers need seven impressions before they make a purchasing decision. A campaign promotes the same message across various channels. The more often they see the campaign on different avenues, the more likely they will take the desired action. That is why advertisements from the same brand name on billboards, on TV, and on Face book. They want to permeate life from all angles (Blasberg, 2019). Advertising envelops not just deciding purchaser needs. It additionally makes buyer needs. It starts with a comprehension of likely customers. One notable $21 \mathrm{st}-$ century advertising disappointment had to do with U.S. organizations' endeavours to sell antiperspirants in China. These U.S. organizations neglected to understand that, organically, ethnic Chinese do not have similar personal stench issues as Westerners. They likewise neglected to consider that Chinese shoppers normally view perspiring as a concrete action that, in addition to other things, refines the framework and not, as is regular among Americans, as a social issue. It is an axiom of showcasing schooling that promoting cannot make a need. Nonetheless, many showcasing efforts depend on making consciousness of an item and the attractive quality. What is significant is that this mindfulness makes the need (Gleeson, 2019).

The rise, multiplication, and universality of the Internet have changed organizations and modified the connection among organizations and clients. Late advances in innovation have helped move this relationship to an intellectual level where innovation adds to mark working by making and supporting a drawn-out relationship with the client. Media fracture and client lack of interest in conventional showcasing devices power advertisers to look for new chances, so the promoting message catches clients' consideration and attempts to draw in them with the organization. Using websites by a few organizations as instruments to all the more likely draw in the client in the creation, conveyance, and spread of advertising messages is likewise illustrated (Tanuja et al., 2008).

There is a gap despite the developing accessibility of client information. Numerous organizations do not complete information examination. An examination uncovered that 54 percent of 159 organizations overviewed conceded they have no framework for overseeing efforts. For most, investigation is not the top of the plan. Organizations are ordinarily zeroing in so eagerly on social event information. They fail to consider why they are gathering them and neglecting to use them to showcasing efforts effectively. The 'ideal to have' instead of the 'need to know' way to deal with client information is to be faulted. The case for building up dynamic promoting technique 
subtleties the key advances, advances, and methodologies needed to accomplish and outline the significance of showcasing effort frameworks and examination in the fight to comprehend client information and guarantee longlasting client faithfulness (Luxton, 2002). Furthermore, the University of Cebu must come up with a compelling campaign to let students' from senior high school decide to enroll in college courses offered by the university.

By the presented situation, the researcher who is in the field of academe teaching Business and Management discipline, currently a faculty member, a Program Research Coordinator, and a Marketing Research subject Instructor determines and analyze the level of perception of Senior High School Students' towards the factor affecting their career choice in the College of Business and Accountancy and the courses offered by UCLM. The researcher will recommend a Campaign Plan to promote the university's continuous improvement and the department by the research conducted. Primarily, this study looked forward to the benefit of the University of Cebu Lapu-Lapu and Mandaue campus, specifically in the College of Business Administration, to enhance and develop its Campaign plan.

\section{FRAMEWORK}

This study is anchored on Social marketing theory by Lee \& Kotler (2016). It is an arrangement of hypotheses that focuses on how socially significant information can be progressed. Social and government help affiliations have used this speculation to help progress or incapacitate various practices. The hypothesis is managerial with a definitive target: it wants to plot a structure that can be utilized to organize, total, and assess data crusades. The normal vested gathering is perceived as dependent on their data need. When this is done, data is bundled and appropriated to be effectively open to the objective gathering. The theory attempts to perceive how social and mental components work to adequately control them to assemble how profitable, wide correspondences information campaigns are. The theory bases on distinctive social and mental deterrents that ruin information course through expansive interchanges and offers considerations and ways to deal with beat these obstructions. These philosophies range from being local to the utilization of submersion publicizing. Features of Social Marketing Theory: Creating Audience Awareness: When there is a need to propel any clever thought, individual or direct, the fundamental development is to make cautious that a particularly notable thought singular exists. Care is made by utilizing all open channels accessible to one, like news media and even new media like the web. Possibly the clearest approach to manage make care has a soaking TV crusade. As indicated by Bajracharya (2018), Social Marketing Theory is a structure that is useful in arranging, planning, actualizing, and assessing social missions with data sharing as its significant target. It utilizes imagination instead of public help declarations, as in the past for giving out data. Data is bundled and conveyed following an arrangement, so most extreme sharing and result is conceivable. Social advertising attempts to comprehend the social and mental components that acquire protection from change society. It expands the adequacy, reaction, and practice of any social thought for the objective gathering. Methods of advertising, like market division, trade hypothesis, and purchaser research, are utilized widely. Social mediation is the main objective of social showcasing. Significant features of Social Marketing Theory: Target crowd examination and division: A specific gathering of populaces in most need of a specific item or mindfulness should initially be investigated to have a social change. The crowd is examined in the preproduction, just as the creation stage.

Likewise, a gathering additionally has different subgroups that must likewise be investigated by separating them, known as crowd division. Existing people group organizations should be utilized. The initial step to social advertising is distinguishing the objective populace. Makes Awareness-Though social promoting is not powerful now and then, to change individuals' standards of conduct, they give mindfulness. Individuals become acquainted with the options that they can receive, so they profit later on. When various channels are utilized to make mindfulness, individuals come to think about new things. Mindfulness is the initial step to change. Increment Interest by Edutainment: The message in social promoting is imaginative and intriguing. Along these lines, the message is not failed to remember for quite a while without any problem. The message is strengthened consistently, and the message is taken as trustworthy by the objective gathering. Instruction and diversion are given as a bundle. Individuals focus just as they get educated simultaneously. For instance, The Street dramatization is not effortlessly failed to remember. Pictures are utilized to expand intrigue and stand out enough to be noticed. Wanted Result: The data should be so fascinating and life-changing that individuals do not take the social promoting cycle to be a learning cycle, however, amusement. When this sort of data arrives at the planned objective gathering, the ideal result is accomplished as the message gets imbued in the audience's mind.

It was also upheld by Hastings \& Saren (2003), expressing an advantageous connection between social, business, and basic promoting thought. Advertisers try to impact purchaser conduct. Many infirmities and numerous social issues are brought about by human conduct. Social promoting assembles these two marvels and uses showcasing experiences to address social practices. Social advertising likewise perceives ecological impacts on conduct and that business showcasing can be a significant piece of this impact. Social showcasing comprehension of both the business and social areas places it in an exceptional situation to give sensible promoting studies and recognize wise arrangements. Connectivism theory also supports the study in which it is a relatively new learning theory, developed and based upon the idea that people process information by forming connections. This theory has developed with the digital and technology age, adapting to 
advances in these areas. This new theory suggests that people no longer stop learning after formal education and continue to gain knowledge from other avenues, for example, work aptitudes, systems administration, experience, and admittance to data with new tools in technology (Siemens, 2005). Connectivism is a learning hypothesis that clarifies how Internet advancements have made new open doors for individuals to learn and share data across the World Wide Web. These advances fuse Web programs, email, wikis, online discussion conversations, relational associations, YouTube, and whatever other contraption, empowering the clients to learn and impart data to others. A critical component of connectivism is that much learning can occur across peer networks on the web. In connectivist learning, an instructor will control understudies to data and answer critical inquiries to help understudies learning and sharing. Understudies are likewise urged to search out data independently on the web and express what they find. An associated network around this shared data frequently results. The massive open online course (MOOC) wonder comes from the connectivist hypothesis. In a connectivist MOOC (cMOOC), it is available to any individual who needs to select. It utilizes open programming and frameworks across the Web to encourage learning and sharing. It happens principally on the web, and it occurs as indicated by a predefined educational program for an assigned period. While facilitators manage the cMOOC, its members are generally liable for what they realize and what and how they share it; this associated conduct, to a great extent, makes the course content (Downes, 2010).

The investigation was additionally upheld by the Program Theory, which gives a good image of how change happens and how to improve execution. The Program Theory tells the best way to create, speak to, and use program hypothesis insightfully and deliberately to suit a specific circumstance. The requirements appraisal to intercession plan, from usage to results assessment, from strategy definition to strategy execution and assessment, program hypothesis is fundamental (Funnell, and Rogers, 2011). Program hypothesis is a bunch of unequivocal or understood suspicions by partners about what activity is needed to settle a social, instructive, or medical condition and why the difficult will react to this activity (Chen, 2012).

Program Theory's motivation is to survey whether an intercession works or does not work and how and why it does as such. The data is basic for partners to improve existing or future projects (Chen, 2012). Program hypothesis is a framework setup of partners' prescriptive suspicions and graphic presumptions entire projects, regardless of whether unequivocal or certain. Different presumptions, called the change model, manage what causal cycles are required to accomplish program objectives. Prescriptive suppositions, called the activity model, manage what moves should be made in a program to create attractive changes. Program hypothesis utilizes the activity model and change model to address relevant factors and arranging, and execution gives that are incredibly keen on partners (Donaldson, 2012).

Further upheld by Action Model is a deliberate arrangement for orchestrating staff, assets, settings, and backing associations to arrive at an objective gathering and convey mediation administrations. The action model consists of the following elements: 1) implementing organization that assesses, enhances, and ensures its capabilities: A program relies on an organization to allocate resources, to coordinate activities, and to recruit, train, and supervise implementers and other staff. How well a program is implemented may be related to how well this organization is structured. It is initially important to ensure that the implementing organization can implement it (Saunders, 2015).

Programs are confounded marvels, by and large resulting from experience and expert legend. At the same time, mentioning an assessment, partners by and large need to know whether they are doing works and improve the intercession. Program hypothesis can frequently give that sort of data without assembling the examination endeavors of powerful investigation. It very well may be contended that the program hypothesis does not reflect how the mediation creates the proposed results, but instead, partners' discernments and convictions, right or off-base, about the systems that work between the conveyance of the intercession and the planned results. The entire hypothesis is then based on the agreement on partner convictions and perceptions (Chen, 2012).

Beliefs and perception are the roots or foundations of the individual's way of thinking. In normal life, we do not question or filter our own beliefs. Perception is the method or way of thinking or point of view. People called it a paradigm. It is the filter of any input based on an individual's beliefs (Teknomo, 2006). A viable dynamic necessitates that subjects shape and keep a conviction about the rightness of decisions in an uncertain and equivocal world. A cycle called metacognition. The expectation of future results and self-checking are just compelling if conviction intently coordinates social execution (Drugowitsch et al., 2014).

\section{OBJECTIVES OF THE STUDY}

The investigation expected to decide the degree of view of senior high school understudies' on the elements influencing their career choice as to personal factors, peer factors, family factors, and school factors. Specifically, it identifies the respondents' demographic profile in terms of age, gender, academic track, and parents' educational background. It also seeks to determine the course preference of the Senior High School understudies' on the university's courses. This study served as the basis for a Sustainable Campaign Plan to ensure its relevance to the students' current and future needs inthe Business and Accountancy department. 


\section{METHODOLOGY}

\section{A. Research Design}

This investigation utilized a descriptive-correlational research method using the self-built study questionnaire to determine the factors affecting senior high school career choice and their preferred courses in the university.

\section{B. Research Environment}

The exploration was conducted at the Senior High School department of the University of Cebu Lapu-Lapu and Mandaue, situated at A.C. Cortes Ave., Mandaue City. The department offers the following strand: ABM, ACAD STEM, GAS, and HUMSS. Furthermore, the online platform through google form was used to gather data.

\section{Research Respondents}

The 200 respondents are the Grade-12 Senior high school students using the Slovins formula on a stratified random sampling technique. The respondents are currently enrolled in the following strand ABM, HUMSS, GAS, and Academic STEM. The location is fit for the research and would give the researchers easy access and response.

\section{Research Instrument}

The investigation utilized a self-built study poll in which the instrument is made out of three parts. The initial segment is the respondent's profile.

The next part is the view of the variables influencing vocation decision concerning personal factors, peer factors, family factors, and school factors. Additionally, the third part contains evaluating the three (3) preferred courses of the students currently offered at the University of Cebu Lapu-Lapu and Mandaue.

\section{E. Treatment of Data}

Frequency and simple percentage, weighted mean, and Chisquare test of Independence were used to treat the accumulated data.

\section{F. Research Procedure}

\section{Data Gathering}

In order to attain the research study, the following steps are determined. Letter of intent will be addressed to the Principal of the Senior High School Department for data gathering, asking permission to conduct the survey and to get the all-out number of enrolled understudies. The survey was managed to the various strands through google form as the main instrument on stratified random sampling. The data was tabulated and analyzed, and a parameter will be used to interpret the responses: (1) Not Sure, (2) Disagree, (3) Agree.

\section{RESULTS AND DISCUSSION}

This part presents the after effects of the information assembled. The underlying section presents the demographics of the respondents. The next part presents the data true to the perspective of senior high understudies on the elements influencing their professional decision.

TABLE I PROFILE OF THE RESPONDENTS (N = 200)

\begin{tabular}{|l|c|c|}
\hline & Frequency & Percentage \\
\hline Age & & \\
\hline 16 & 84 & 42.00 \\
\hline 17 & 83 & 41.50 \\
\hline 18 & 31 & 15.50 \\
\hline 19 & 2 & 1.00 \\
\hline Gender & & \\
\hline Male & 77 & 38.50 \\
\hline Female & 123 & 61.50 \\
\hline Academic Track & & \\
\hline ABM & 50 & 25.00 \\
\hline HUMMS & 50 & 25.00 \\
\hline STEM & 50 & 25.00 \\
\hline GAS & 50 & 25.00 \\
\hline $\begin{array}{l}\text { Parents Educational } \\
\text { Background }\end{array}$ & & \\
\hline 1st to 11th grade & 23 & 11.50 \\
\hline High School Graduate & 81 & 40.50 \\
\hline Some College & 36 & 18.00 \\
\hline College Graduate & 58 & 29.00 \\
\hline Post Graduate & 2 & 1.00 \\
\hline
\end{tabular}

Table I shows the respondents' profile based on age, gender, academic track, and parent's educational attainment showing respondents aged 16-17 years old got the highest equivalent at 42 percent, respectively. It implies that Senior High students' are at the young adult stage.

It was further supported by the Education State University (2019), stating that Advanced education in the Philippines is as a rule from 17 to 20 years of age. Concerning sexual orientation majority share or 61.50 percent of the respondents were females. It shows that the female has more tendencies to take the projects in the Senior High School Department.

The Academic Track has been isolated as needs be and proportionate with 50 respondents each strand or identical to 25 percent. As per Katigbak (2019), since its endorsement in 2013, the K-12 framework has made changes in how secondary school understudies are prepared 
for instructive headway and viable business. The K-12 program added two more scholastic schools a very long time to the then-existing 10-year pre-college configuration of auxiliary training organizations. The K-12 program expects to outfit understudies with the genuinely necessary abilities to pick up work even without higher education. There are four potential tracks to browse: Academic, Sports, Arts and Design, and Technical-Vocational-Livelihood tracks. Four unique strands fall under the Academic track:
Accounting, Business, and Management (ABM) strand, Science, Technology, Engineering and Mathematics (STEM) strand, Humanities and Social Sciences (HUMSS) strand, and the General Academics strand. Most are at a secondary school level regarding the family's educational background, indistinguishable from 40.50 percent. It surmises that a huge bit of the respondents people were secondary school graduates.

TABLE II LEVEL OF PERCEPTION ON THE FACTORS AFFECTING CAREER CHOICE AS REVEALED BY THE RESPONDENTS

\begin{tabular}{|c|c|c|c|}
\hline Factors Affecting Career Choice & Mean & Interpretation & Rank \\
\hline \multicolumn{4}{|l|}{ Personal Factor } \\
\hline The course preference suits personal talent. & 2.62 & Agree & 1 \\
\hline Considers the course that has a higher salary in the future. & 2.51 & Agree & 2 \\
\hline Course preference depends on personal mental capacity. & 2.51 & Agree & 2 \\
\hline The course preference is a "childhood dream." & 2.22 & Disagree & 3 \\
\hline Course preference depends on the individual's available time. & 2.06 & Disagree & 4 \\
\hline Aggregate Mean & 2.38 & Agree & \\
\hline \multicolumn{4}{|l|}{ Peer Factor } \\
\hline A friend's choice of school affects career choice. & 2.62 & Agree & 1 \\
\hline Prefer a course where a friend is studying. & 2.62 & Agree & 1 \\
\hline Considers the course that can easily be accomplished. & 2.26 & Disagree & 2 \\
\hline Friend's preference for a career effect's individuals career choice. & 2.21 & Disagree & 3 \\
\hline Considers the rumors of the course, that sounds good. & 2.19 & Disagree & 4 \\
\hline Aggregate Mean & 2.38 & Agree & \\
\hline \multicolumn{4}{|l|}{ Family Factor } \\
\hline Considers the courses that are not yet taken by a family member. & 2.32 & Disagree & 1 \\
\hline Family structure affects career choice. & 2.32 & Disagree & 1 \\
\hline Considers the dominant profession in the family in choosing a career. & 2.23 & Disagree & 2 \\
\hline Parents choose individuals' careers. & 2.01 & Disagree & 3 \\
\hline Considers the financial status of the family. & 1.97 & Disagree & 4 \\
\hline Aggregate Mean & 2.17 & Disagree & \\
\hline \multicolumn{4}{|l|}{ School Factor } \\
\hline Considers the reputation of the school. & 2.56 & Agree & 1 \\
\hline Considers the school uniform in choosing the course. & 2.37 & Agree & 2 \\
\hline Considers the schools' tuition fee in a career choice. & 2.37 & Agree & 2 \\
\hline Considers the school prestige & 2.29 & Disagree & 3 \\
\hline Considers the distance of the school. & 2.29 & Disagree & 3 \\
\hline Aggregate Mean & 2.37 & Agree & \\
\hline
\end{tabular}

Table II shows the degree of the impression of the variables influencing professional choices seen by the respondents. As for personal factors, the indicator which courses preference suits to students' talent got the highest mean of 2.62 and interpreted as Agree. This means that students' talent and skill are a vital personal factor that affects career choice. The indicator that considers course preference depends on the available time got the lowest mean of 2.06 and interpreted as Disagree. It infers that the availability of time does not contribute as a personal factor affecting their career choice. According to Twumasi et al., (2018), great professional arranging prompts life satisfaction featuring individual interest as the main consideration. It impacts vocation decisions in individualistic settings delivering the adolescent more autonomous in their professional decisionmaking. Concerning peer factor, an indicator which friends' choice of school affects career choice got the highest mean of 2.62 and interpreted as Agree. It implies that friends' 
choice of school as a peer factor directly affects students' career choice. On the other hand, the indicator which considers rumors of the course that sounds good to the respondent got the lowest mean of 2.19 and interpreted as Disagree. It implies that a rumor about a certain course does not contribute as a peer factor in the respondents' career choice.

According to Naz et al., (2014), peer influence is an asset for developing career opportunities and youth decisionmaking. Peer and friends overwhelm in informed decisions and vocation emotional cycle. Moreover, peers and friends have a positive role in selecting subjects, selecting a class, selecting a laboratory, library, books, and facilitation in homework and co-curricular activities.

The statistics regarding career decision-making show that peer and friends help in career decision-making, professional career, helping in selecting a job, helping in employment opportunities, and earning tendencies are mostly influenced by peer and friends.

Concerning the family factor, an indicator that considers courses that are not yet taken by the family got the highest mean of 2.32 and interpreted as Disagree. It implies that this indicator does not affect the career choice of the students. On the other hand, the indicator that considers the family's financial status got the lowest mean of 1.97 and interpreted as Disagree. It means that family financial status does not contribute to the perception of students' career choice. Family factor among the respondents does not contribute and affects their choice in their career path, revealing that family structure and financial status are not hindrances to success.

A few people say they thought poverty is not an obstacle to progress. It is a fantasy. Like this, they prefer to reprimand the possibility that difficult work, positive reasoning will empower one to conquer destitution. Poverty is a type of achievement. Effective at being neediness bound is the reason such countless individuals are fruitful. There is no limit to progress since we are altogether effective at what we do. They did not grow up favored, neither did they go to great schools, and regardless, they did not have exceptional associations, yet they got fruitful.

In any case, what they share is their devotion and hard work (Karikari, 2015). Concerning the school factor, the indicator which considers the school reputation got the highest mean of 2.56 and interpreted as Agree. It implies that the school reputation as a school factor directly affects the students' career choice. On the other hand, indicator which considers the distance of the school got the lowest mean of 2.29 and interpreted as Disagree. It means that the school distance as school factor does not affect the students' career choice.

The decision of a course and which school to enter school is one of the significant choices looked at by the graduating understudies, which is a significant component of their learning cycle. The course and school selection decision will most likely define their future success (Dayao \& Almario, 2017).

TABLE III LEVEL OF ASSESSMENT ON THE PREFERRED COURSES AS REVEALED BY THE RESPONDENTS

\begin{tabular}{|l|c|c|}
\hline $\begin{array}{c}\text { Course } \\
\text { Preferences }\end{array}$ & Mean & Rank \\
\hline BSED ENGL & 2.36 & 1 \\
\hline BSA & 2.27 & 2 \\
\hline BSN & 2.15 & 3 \\
\hline BSEE & 2.14 & 4 \\
\hline BSIE & 2.11 & 5 \\
\hline HRDM & 2.09 & 6 \\
\hline BSHRM & 2.09 & 6 \\
\hline CRIM & 2.08 & 7 \\
\hline BSED FIL & 1.89 & 8 \\
\hline MM & 1.88 & 9 \\
\hline BSCA & 1.88 & 9 \\
\hline BEED & 1.85 & 10 \\
\hline BSMT & 1.84 & 11 \\
\hline IS & 1.82 & 12 \\
\hline FM & 1.80 & 13 \\
\hline CS & 1.80 & 13 \\
\hline BSECE & 1.75 & 14 \\
\hline BSED MATH & 1.75 & 14 \\
\hline CE & 1.64 & 15 \\
\hline
\end{tabular}

Table III shows the degree of perception assessment on the preferred courses as revealed by the respondents. The data revealed that the respondents' three most preferred courses are BSED English, Accountancy, and Nursing courses. It implies that most students are inclined to pursue the courses mentioned on their baccalaureate degree in College. It means also that not all courses pertaining to the Business and Accountancy are most likely preferred by the students' in the senior high school department.

According to Dayao \& Almario (2017), the provision of a more intensive internal marketing program is suggested in determining which program or service is made available to senior high students singly or in a combination that could be determinants of their retention. Further, importance in the Later Goals and Institutional Commitment, it did not ensure understudy maintenance.

The factor that resounds behind might be the accessibility of alternatives that the understudies can continue after their senior secondary school (Dalangin, 2018). 
TABLE IV RELATIONSHIP BETWEEN THE RESPONDENTS' PROFILE AND THE FACTORS AFFECTING CAREER CHOICE $(\propto=0.05)$

\begin{tabular}{|l|c|c|c|c|c|}
\hline \multicolumn{1}{|c|}{ Variables } & $\begin{array}{c}\text { Computed } \\
\text { Chi-Square }\end{array}$ & df & $\begin{array}{c}\text { Critical } \\
\text { Value }\end{array}$ & Significance & \multicolumn{1}{c|}{ Result } \\
\hline Gender \& factors on career choice & $4.099^{\mathrm{a}}$ & 6 & 12.592 & Not Significant & Accept Ho \\
\hline Academic Track \& factors on career choice & $33.546^{\mathrm{a}}$ & 18 & 28.869 & Significant & Reject Ho \\
\hline Educational Attainment \& factors on career choice & $33.277^{\mathrm{a}}$ & 24 & 36.415 & Not Significant & Accept Ho \\
\hline
\end{tabular}

Table IV shows the relationship between the respondent's profile and the factors affecting their career choice. The data revealed a statistically significant relationship between academic track and students' career choice (p-value<.05). However, gender and family educational attainment does not statistically relate to the factors affecting students' career choice. As indicated by the Asian Development Bank \& Deped (2019), the K to 12 Basic Education Program's utilization in the Philippines fuses introducing senior
Auxiliary school (SHS), or grades 11 and 12, the last two years in a new6-year optional training framework. While previous curricula focused mainly on postsecondary education readiness, the SHS curriculum aims to prepare students for further education or employment. Additionally, to give adequate opportunity to the authority of ideas and abilities, create deep-rooted students, and plan graduates for tertiary schooling, center level aptitudes improvement, work, and business venture.

TABLE V RELATIONSHIP BETWEEN THE RESPONDENTS PREFERRED COURSES AND THE

FACTORS AFFECTING CAREER CHOICE $(\propto=0.05)$

\begin{tabular}{|l|c|c|c|c|c|}
\hline \multicolumn{1}{|c|}{ Variables } & $\begin{array}{c}\text { Computed } \\
\text { Chi-Square }\end{array}$ & df & Critical Value & Significance & Result \\
\hline Personal Factor \& Course Preference & $385.976^{\mathrm{a}}$ & 54 & 72.153 & Significant & Reject Ho \\
\hline Peer Factor \& Course Preference & $70.786^{\mathrm{a}}$ & 60 & 79.082 & Not Significant & Accept Ho \\
\hline Family Factor \& Course Preference & $65.654^{\mathrm{a}}$ & 60 & 79.082 & Not Significant & Accept Ho \\
\hline School Factor \& Course Preference & $69.551^{\mathrm{a}}$ & 54 & 72.153 & Significant & Reject Ho \\
\hline
\end{tabular}

Table V shows the relationship between the respondent's preferred courses and the factors affecting their career choice. The data revealed a statistically significant relationship between personal factors, school factors, and the respondents' course ( $\mathrm{p}$-value<.05). It implies that both personal and school factors have a direct effect on the decision making made by the students' relating to their career choice. However, peer factors and family factors do not significantly relate to the course preferred by the students. Students' career decision-making is most profoundly influenced by close to home elements, bunch factors, vocation investigation factors, and school factors. Also, the usage of instruction projects is essentially centered around understudies' requirements for professional advancement. Regarding understudies, schools are the key factor influencing understudies' vocation dynamic since school training can help understudies complete the profession investigation, the inspiration of searching for occupations, and the impression of their professional objectives (Su et al., 2016).

\section{RECOMMENDATIONS}

Given the discoveries of the examination, the researchers proposed an Intervention Scheme on the period of a Business and Accountancy Campaign Plan which decides the mission systems and materials that ought to be utilized to support the number of enrolees in the CBA, specifically to those Business Administration Majors which got the most minimal positions. To limit or recognize professional decision issues, it is important to help the understudies get rational decision-making. The Business and Accountancy Department must conduct an extensive campaign program to attract more students to enroll. It is essential to have it so understudies would be completely mindful of the various majors that the office has and how it can help them on the accessibility of future positions and the openness of these positions in our nation.

The mindfulness also regards remuneration and advantages. The CBA should conduct a career Orientation Program for those graduating Senior High School students. This seminar should have enough time to finalize their choice and avoid costly shifting to another course, and students will not be disoriented in the new environment.

Production of a Social Media source or a page wherein understudies and non-understudies of UCLM can peruse and check the various majors advertised. The activities are done by the department throughout the school year to attract more enrolees and will serve as a Marketing tool as well.

A brochure and fliers should also be created containing the department's different achievements, equipment, facilities, and faculty members. The college and its organizations ought to liberally uphold the Department in executing the said Campaign Plan. Future specialists are enthusiastically prescribed too to affirm the noteworthiness of this investigation additionally. 


\section{CONCLUSION}

Marketing campaigns helps create a strong brand identity and voice. They maintain consistency among advertisements, promoting a unified brand message across all platforms. The study revealed that personal factors, peer factors, and school factors are the most common perception in students' career decision making. However, family factors highlighting financial and structure concerning its negativity of thought do not influence students' career choice. Thereby empowering, is not always a hindrance to success, and considering that if there is a will, there is always a way. The study also revealed that BSED in English, Accountancy, and Nursing is the most preferred senior high courses. Furthermore, a statistically significant relationship between academic track and students' perception of the factors that affect career choice was also uncovered. Lastly, there is also a statistically significant relationship on the personal factors, school factors on the most preferred courses of the respondents. The study concluded that senior high school students' must be guided to achieve a good decision pursuing courses offered by the Business and Accountancy department. A campaign program is inevitable to realize the set objectives higher and to prepare for future student encounters.

\section{REFERENCES}

[1] Asian Development Bank \& Deped (2019). Youth Education Invest ment and Labor Market Outcomes in the Philippines: Survey Report. Retrieved from https://bit.ly/2LmGEGT.

[2] Bajracharya, S. (2018). Social Marketing Theory. Retrieved from https://bit.ly/2pfaUIJ.

[3] Blasberg, M. (2019). Making a mess of your marketing? Here is the Ultimate Campaign Planning Guide. Retrieved from https://bit.ly/2nvF0qV.

[4] Chen, H. T. (2012). Theory-driven evaluation: Conceptual framework, application, and advancement. Retrieved from https://bit.ly/2IcO0sP

[5] Dalangin, JJ, G. (2018). Factors Affecting Student Retention at De La Salle Araneta University. Journal of Global Business. 7,287-295. Retrieved from https://bit.ly/3s 0 WrvB
[6] Dayao, R., \& Almario., O. (2017). Career and School Preferences Of Senior High School Students Academic Year 2017-2018. Intern ational Journal of Advanced Research, 5(11), 1219-1222. Retrieved from https://bit.ly/35egTPS.

[7] Donaldson, S. (2012). Strategies and Applications: Program TheoryDriven Evaluation Science. Hove, East Sussex BN3 2FA, New York: Routledge. Retrieved from https://bit.ly/2m4KjfJ.

[8] Downes,S.(2010).New technology supporting informal learning. Journal of Emerging Technologies in Web Intelligence, 2(1), 27-33. Retrieved from https://bit.ly/2mStsO0

[9] Funnell, C., \& Rogers, P. J. (2011). Purposeful Program Theory: Effective Use of Theories of Change and Logic Models. Retrieved from https://bit.ly/2kAyTzN

[10] Gleeson, P. D. (2019). The Importance of Marketing for the Success of a Business. IRetrieved from https://bit.ly/2mO3Vpb

[11] Hastings, G., \& Saren, M. (2003).The Critical Contribution of Social Marketing. Marketing Theory,3(3), 305-322. Retrieved from https://bit.ly/2L3r96D

[12] Karikari, K. B. (2015). Poverty Not A Hindrance to Success. Modern Ghana. Retrieved from https://bit.ly/35dCEQ6.

[13] Lee, N., \& Kotler, P. (2016). Social marketing: changing behaviors for good. Thousand Oaks, CA: SAGE. Retrieved from https://bit.ly/2p95Xk1

[14] Naz, A., Saeed, G., Khan, W., Khan, N., Sheikh. I., \& Khan, N. (2014). Peer and Friends and Career Decision Making: A Critical Analysis. Middle-East Journal of Scientific Research, 22 (8): 11931197. Retrieved from https://bit.ly/3rWPKuD

[15] Saunders, R. (2015). Implementation of Monitoring and Process Evaluation. The United States of America: SAGE Publications, Inc. Retrieved fromhttps://bit.ly/2KXlf4C

[16] Su, M. S., Chang, T. C., Wu, C. C., \& Liao, C. W. (2016). Factors Affecting the Student Career Decision-Making of Junior high school students in Central Taiwan Area. International Journal of Information and Education Technology, 6(11), Retrieved from https://bit.ly/2L93Nwq

[17] Teknomo, K (2006). What are Belief, Perception, and Attitude?. Retrieved from: https://people. revoledu.com /kardi/Idea/ smartness/BeliefPerceptionAttitude.htm

[18] Tanuja Singh, Liza Veron-Jackson, Joe Cullinane, Blogging. (2008) A new play in your marketing game plan, Business Horizons, 51,( 4), 2008, Pages 281-292, ISSN 0007-6813. Retrieved from https://bit.ly/2XoOySV

[19] Twumasi, P. A., Emeto, T. I., Lindsay, D., Tsey, K., \& Aduli, B.M (2018). A Systematic Review of Factors That Influence Youths Career Choices-the Role of Culture. Frontiers in Education. 3, 58. Retrieved from https://bit.ly/38fX6S3. 